\title{
The Incidence and Mortality of Cancer in Eastern Mediterranean Regional Office (EMRO) and Its Relationship with Human Development Index (HDI): An Ecological Study
}

\author{
Zaher Khazaei ${ }^{1}$, Mojgan Navabi ${ }^{2}$, Isan Darvishi ${ }^{3}$, Elham Goodarzi ${ }^{2}$
}

${ }^{1}$ Student Research Committee, Sabzevar University of Medical Sciences, Sabzevar, Iran. ${ }^{2}$ Social Determinants of Health Research Center,Lorestan University of Medical Sciences, Khorramabad, Iran. ${ }^{3}$ MSc of Surgical Technology, Surgical Technology Department, School of Nursing and Midwifery, Shiraz University of Medical Sciences and Healthcare Services, Shiraz, Iran.

\begin{abstract}
Background and objective: the cancer was considered as the second cause of mortality in the developed countries and all around the world after the cardiovascular diseases. Also, it was reported as the third cause of mortality in the less developed countries after cardiovascular diseases. The current study was aimed to evaluate the epidemiology, incidence, and mortality of all cancers in East-Mediterranean region by gender and age. Materials and methods: This study was an ecologic study in Asia for assessment of the correlation between age-specific incidence rate (ASIR) and age-specific mortality rate (ASMR) with HDI (life expectancy at birth, mean years of schooling and gross national income (GNI) per capita) Data about SIR and SMR for every Asian country for the year 2012 were obtained from the global cancer project. Correlation bivariate method for assessment of the correlation between incidence and mortality rates was used. Statistical analysis using Stata-14 and P 05/0, respectively and a significant $<0.05$. Results: in East-Mediterranean region, some 555318 cases of cancer recorded in 2012. The highest incidence rates of cancer were reported for breast, colo-rectum, lung, liver, and bladder being $17.9 \%, 5.9 \%, 5.9 \%, 5.3 \%$, and $5 \%$, respectively. Also, the highest mortality of cancer were reported for breast, colo-rectum, lung, liver, and bladder being $11.5 \%, 5.8 \%, 5.9 \%, 7.6 \%$, and 3.8\%, respectively. The highest and lowest mortality ratios were reported for Somalia, and Saudi Arabia being 106.2, and 53.9 cases per 100000 people, respectively. Lung cancer and Human Development Index (HDI) had significant correlation with each other $(\mathrm{P}>0.05)$. Also, a significant correlation was seen between Human Development Index (HDI) and mortality rates of breast, colorectal, lung and liver cancer $(\mathrm{P}>0.05)$. Conclusion: the cancer was considered as one of the main causes of mortality in the most countries of East-Mediterranean region. The breast and colorectal cancers were reported as the most common types of cancer in this region. As for the alarming trend and remarkable distribution of cancer to the disease load in East-Mediterranean countries, controlling the cancer should be considered as one of the priorities of health policy.
\end{abstract}

Keywords: Cancer- incidence- mortality- Eastern Mediterranean Regional Office (EMRO)

Asian Pac J Environment and Cancer, 1 (1), 59-67

\section{Introduction}

Maintaining and promoting the human being health need the enough information, screening of the current situation, and correct selection of future priorities. Preventing and controlling the noncontagious and chronic diseases were considered as one of the most important priorities of healthcare system. The noncontagious and chronic diseases were superseded for contagious
Submission Date: 08/20/2018 Acceptance Date: 10/26/2018

Corresponding Author:

Dr. Elham Goodarzi

Social Determinants of Health Research Center,Lorestan University of Medical Sciences, Khorramabad, Iran.

Email: Elhamgoodarzi.1370@yahoo.com 
noncontagious diseases. Some one-fourth of mortality rate could be related to the cancers reported as one of the most important healthcare issues of the societies especially following the western life style [8]. The studies reported a $45 \%$ rate of mortality related to noncontagious diseases right across the world in the years conducing 2015 while the rate of cancer-related mortality was estimated as $10 \%$ [9].

The cancers were considered as the most important Non-communicable diseases constraining the main load of sickness on the society. On the other hand, the relative control of contagious diseases, life expectancy increase, changing the life style, increasing the environmental risk factors, genetic property, and society aging were indicated as the multiplier factors of the disease in the recent and future decade s [10-11].

The cancer results from the abnormal pretension and expression of the gene. The quick growth of cancer cells in the priory location emerges the symptoms by destruction mechanism and filling the available space. They also emerges the specific symptoms and signs in the involved organ by progressing through blood and lymphatic system and metastasis [12]. The cancer might be indicated as one of the most important factors of the disease load in the world in the future decades. The rate of new cases of this disease might be estimated as 15 million people in 2020 [7-13].

More than half of the cancers would be broken out in the developing countries such as Southern-America and Asia countries. Some three-fourth of the people in these countries is living with the low and average salaries. The rate of cancer survivors in the developing countries accounts for one-third of the people living in the developed countries. Some 9 million new cases of cancer break out contributing 4 million people for the developed countries as compared to the 5 million people in the developing ones [13-14].

Some $54 \%$ of the overall mortality might be due to noncontagious diseases till 2015. In this between, the cancer plays an important role and its rate was predicted to $13 \%$ of the overall mortality across the world. Furthermore, the studies suggested the cancer as the first and most important cause of mortality in 2030 [15]. Therefore, the current study was aimed to evaluate the epidemiology, incidence, and mortality of all cancers in East-Mediterranean region by gender and age differences using the cancer World Bank information.

\section{Materials and Methods}

In the current study, the incidence and mortality rates of all cancers in East-Mediterranean region related data were extracted on behalf of the Cancer Global Project in 2012 available at http://globocan.iarc.fr/Default.aspx.

The methods of estimation are country specific and the quality of the estimation depends upon the quality and on the amount of the information available for each country. In theory, there are as many methods as countries, and because of the variety and the complexity of these methods, an overall quality score for the incidence and mortality estimates combined is almost impossible to establish. However, an alphanumeric scoring system which independently describes the availability of incidence and mortality data was established at the country level. The combined score is presented together with the estimates for each country with an aim of providing a broad indication of the robustness of the estimation.

\section{Estimation incidence}

The methods to estimate the gender- and age-specific incidence rates of cancer for a specific country fall into one of the following broad categories, in priority order: 1 . Rates projected to 2012 (38 countries) 2. Most recent rates applied to 2012 population (20 countries) 3. Estimated from national mortality by modelling, using incidence mortality ratios derived from recorded data in countryspecific cancer registries (13 countries) 4. Estimated from national mortality estimates by modelling, using incidence mortality ratios derived from recorded data in local cancer registries in neighboring countries (9 European countries) 5 . Estimated from national mortality estimates using modelled survival (32 countries) 6. Estimated as the weighted average of the local rates (16 countries) 7 . One cancer registry covering part of a country is used as representative of the country profile (11 countries) 8. Age/ gender specific rates for "all cancers" were partitioned using data on relative frequency of different cancers (by age and gender) (12 countries) 9. The rates are those of neighboring countries or registries in the same area (33 countries).

\section{Estimation mortality}

Depending of the degree of detail and accuracy of the national mortality data, six methods were utilized in the following order of priority: 1. Rates projected to 2012 (69 countries) 2. Most recent rates applied to 2012 population (26 countries) 3. Estimated as the weighted average of regional rates ( 1 country) 4 . Estimated from national incidence estimates by modelling, using country-specific survival ( 2 countries) 5 . Estimated from national incidence estimates using modelled survival ( 83 countries) 6 . The rates are those of neighboring countries or registries in the same area (3 countries) [16]. http://globocan.iarc.fr/ Default.aspx.

\section{$H D I$}

The HDI is a composite measure of indicators along three dimensions: life expectancy, educational attainment, and command over the resources needed for a decent living. All groups and regions have seen notable improvement in all HDI components, with faster progress in low and medium HDI countries. On this basis, the world is becoming less unequal. Nevertheless, national averages hide large variations in human experience. Wide disparities remain within countries of both the North and the South; income inequality within and between many countries has been rising [17-18].

\section{Statistical analysis}

In this study, we used the correlation bivariate method 
for assessment of the correlation between the incidence and mortality rates of cancer and the HDI. We also used linear regression models for assessment of the HDI effect on cancer occurrence rates . The significance level of 0.05 was considered. Data were analyzed by Stata computer software version 12 .

\section{Results}

In East-Mediterranean region, some 555318 cases of cancer were registered in 2012. The highest incidence ratios of cancer in East-Mediterranean region were reported in Lebanon, Jordan, Egypt, and Syrian Arab Republic being 197.7, 155.4, 152, and 145.9 cases per 100000 people, respectively. The lowest incidence ratios of the overall cancers were reported in Yemen, and Oman being 80.4 , and 82.1 cases per 100000 people, respectively (Figure 1).

The highest incidence rates of cancer in males were reported for lung, bladder, liver, prostate gland, and colo-rectum being $12.6 \%, 10.9 \%, 7.9 \%, 7.9 \%$, and $8.3 \%$, respectively as compared to the highest incidence rates of

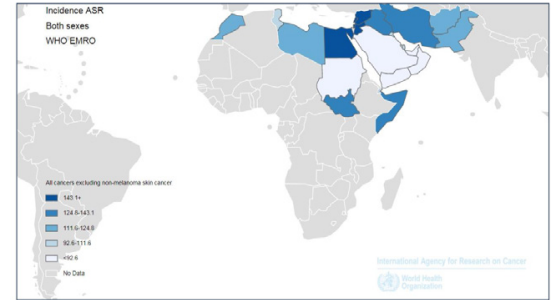

Figure 1. Distribution of the Standardized Incidence Rate of all Cancer in EMRO at 2012 (Extracted from Globocan)

cancer for breast, colo-rectum, cervix uteri, and ovary in females being $41.9 \%, 6.6 \%, 6.4 \%$, and $5.3 \%$, respectively. The highest rates of cancer in both genders were related to breast, colorectum, lung, liver, and bladder being 17.9\%, $5.9 \%, 5.9 \%, 5.3 \%$, and 5\%, respectively (Table 1 ).

The highest incidence rates of breast cancer were reported in Lebanon, Jordan, and Pakistan being 87.7\%, $61 \%$, and $50.3 \%$, respectively. The highest incidence rates of colorectal cancer were reported in Jordan, Syrian

Table 1.Incidence of all Cancer in EMRO by Sex

\begin{tabular}{|c|c|c|c|c|c|c|c|c|c|}
\hline \multirow[t]{2}{*}{ Cancer site } & \multicolumn{3}{|c|}{ Male } & \multicolumn{3}{|c|}{ Female } & \multicolumn{3}{|c|}{ Both Sexes } \\
\hline & Number & $\%$ & $\operatorname{ASR}(W)$ & Number & $\%$ & $\operatorname{ASR}(W)$ & Number & $\%$ & $\operatorname{ASR}(\mathrm{W})$ \\
\hline $\begin{array}{l}\text { All cancers excl. nonmelanoma } \\
\text { skin cancer }\end{array}$ & 262641 & 100.0 & 119.5 & 292677 & 100.0 & 126.2 & 555318 & 100.0 & 122.2 \\
\hline Lip, oral cavity & 11601 & 4.4 & 5.1 & 9080 & 3.1 & 4.1 & 20681 & 3.7 & 4.6 \\
\hline Nasopharynx & 2958 & 1.1 & 1.2 & 1405 & 0.5 & 0.6 & 4363 & 0.8 & 0.9 \\
\hline Other pharynx & 2936 & 1.1 & 1.4 & 1857 & 0.6 & 0.8 & 4793 & 0.9 & 1.1 \\
\hline Esophagus & 9098 & 3.5 & 4.4 & 7945 & 2.7 & 3.7 & 17043 & 3.1 & 4.0 \\
\hline Stomach & 14951 & 5.7 & 7.2 & 8503 & 2.9 & 3.9 & 23454 & 4.2 & 5.5 \\
\hline Colorectal & 18105 & 6.9 & 8.3 & 14664 & 5.0 & 6.6 & 32769 & 5.9 & 7.4 \\
\hline Liver & 19844 & 7.6 & 9.7 & 9523 & 3.3 & 4.5 & 29367 & 5.3 & 7.1 \\
\hline Gallbladder & 2006 & 0.8 & 1.0 & 3503 & 1.2 & 1.7 & 5509 & 1.0 & 1.3 \\
\hline Pancreas & 4503 & 1.7 & 2.2 & 3183 & 1.1 & 1.5 & 7686 & 1.4 & 1.9 \\
\hline Larynx & 9154 & 3.5 & 4.5 & 1422 & 0.5 & 0.7 & 10576 & 1.9 & 2.5 \\
\hline Lung & 25592 & 9.7 & 12.6 & 6950 & 2.4 & 3.3 & 32542 & 5.9 & 7.9 \\
\hline Melanoma of skin & 917 & 0.3 & 0.4 & 898 & 0.3 & 0.4 & 1815 & 0.3 & 0.4 \\
\hline Breast & -- & -- & -- & 99284 & 33.9 & 41.9 & 99284 & 17.9 & 41.9 \\
\hline Prostate & 18585 & 7.1 & 9.7 & -- & -- & -- & 18585 & 3.3 & 9.7 \\
\hline Testis & 2843 & 1.1 & 0.9 & --- & -- & -- & 2843 & 0.5 & 0.9 \\
\hline Cervix uteri & -- & -- & -- & 14861 & 5.1 & 6.4 & 14861 & 2.7 & 6.4 \\
\hline Corpus uteri & -- & -- & -- & 7609 & 2.6 & 3.5 & 7609 & 1.4 & 3.5 \\
\hline Ovary & -- & -- & -- & 12354 & 4.2 & 5.3 & 12354 & 2.2 & 5.3 \\
\hline Kidney & 5399 & 2.1 & 2.4 & 3553 & 1.2 & 1.5 & 8952 & 1.6 & 1.9 \\
\hline Bladder & 21901 & 8.3 & 10.9 & 5789 & 2.0 & 2.8 & 27690 & 5.0 & 6.8 \\
\hline Brain,nervous system & 11159 & 4.2 & 4.3 & 8413 & 2.9 & 3.4 & 19572 & 3.5 & 3.9 \\
\hline Thyroid & 2836 & 1.1 & 1.2 & 9004 & 3.1 & 3.5 & 11840 & 2.1 & 2.3 \\
\hline Hodgkin lymphoma & 5091 & 1.9 & 1.8 & 3283 & 1.1 & 1.1 & 8374 & 1.5 & 1.5 \\
\hline Non-Hodgkin lymphoma & 15893 & 6.1 & 6.6 & 10743 & 3.7 & 4.6 & 26636 & 4.8 & 5.6 \\
\hline Multiple myeloma & 2515 & 1.0 & 1.2 & 1746 & 0.6 & 0.8 & 4261 & 0.8 & 1.0 \\
\hline Leukemia & 13713 & 5.2 & 5.1 & 9679 & 3.3 & 3.7 & 23392 & 4.2 & 4.4 \\
\hline
\end{tabular}


Table 2. Distribution Incidence of 5 Common Cancers in EMRO by Country and Sex

\begin{tabular}{|c|c|c|c|c|c|c|c|c|c|c|c|c|c|c|c|}
\hline \multirow[t]{2}{*}{ Areas } & \multicolumn{3}{|c|}{ Breast } & \multicolumn{3}{|c|}{ Colorectal } & \multicolumn{3}{|c|}{ Lung } & \multicolumn{3}{|c|}{ Liver } & \multicolumn{3}{|c|}{ Bladder } \\
\hline & $\mathrm{F}$ & $\mathrm{M}$ & $\begin{array}{l}\text { Both } \\
\text { Sexes }\end{array}$ & $\mathrm{F}$ & M & $\begin{array}{l}\text { Both } \\
\text { Sexes }\end{array}$ & $\mathrm{F}$ & M & $\begin{array}{l}\text { Both } \\
\text { Sexes }\end{array}$ & $\mathrm{F}$ & $\mathrm{M}$ & $\begin{array}{l}\text { Both } \\
\text { Sexes }\end{array}$ & $\mathrm{F}$ & M & $\begin{array}{l}\text { Both } \\
\text { Sexes }\end{array}$ \\
\hline \multicolumn{16}{|l|}{---- } \\
\hline Afghanistan & 35.0 & -- & 35.0 & 3.6 & 6 & 4.8 & 3.4 & 10.3 & 6.9 & 3.8 & 6.6 & 5.2 & 1.5 & 5.1 & 3.3 \\
\hline Bahrain & 42.5 & -- & 42.5 & 11.0 & 11.8 & 11.4 & 8.5 & 21.3 & 15.5 & 3.4 & 3.6 & 3.5 & 2.1 & 9.6 & 6.3 \\
\hline Djibouti & 35.9 & -- & 35.9 & 5.0 & 7.4 & 6.1 & 2.5 & 2.9 & 2.7 & 2.5 & 4 & 3.2 & 1.1 & 3.5 & 2.2 \\
\hline Egypt & 49.5 & --- & 49.5 & 5.2 & 6.1 & 5.6 & 3.8 & 11.2 & 7.2 & 14.1 & 38.1 & 25.6 & 5.6 & 21.8 & 13.1 \\
\hline Iran & 28.1 & -- & 28.1 & 10.5 & 11.6 & 11.1 & 5 & 10.3 & 7.7 & 2.1 & 2.8 & 2.5 & 3.4 & 13.2 & 8.4 \\
\hline Iraq & 42.5 & -- & 42.5 & 6.5 & 8 & 7.1 & 6.6 & 24.2 & 14 & 3.7 & 4.4 & 4 & 5.2 & 19.9 & 11.4 \\
\hline Jordan & 61.0 & --- & 61.0 & 21.2 & 29.8 & 25.6 & 4.1 & 27.0 & 15.7 & 3 & 5.4 & 4.2 & 1.8 & 12.3 & 7.1 \\
\hline Kuwait & 46.7 & -- & 46.7 & 13.3 & 12.6 & 12.8 & 4.8 & 9.9 & 8.0 & 1.9 & 5.3 & 4.0 & 2.7 & 7.1 & 5.5 \\
\hline Lebanon & 78.7 & -- & 78.7 & 13.5 & 19.1 & 16.1 & 11.0 & 30.2 & 19.8 & 1.9 & 3.3 & 2.5 & 6.1 & 29.1 & 16.6 \\
\hline $\begin{array}{l}\text { Libyan Arab } \\
\text { Jamahiriya }\end{array}$ & 24.1 & -- & 24.1 & 14.3 & 14.6 & 14.5 & 3.7 & 28.0 & 15.7 & 4.1 & 5.4 & 4.8 & 2.3 & 15.3 & 8.6 \\
\hline Morocco & 40.8 & -- & 40.8 & 7.3 & 9.9 & 7.3 & 2.8 & 25.5 & 2.8 & 1.0 & 1.5 & 1.0 & 1.3 & 10.8 & 1.3 \\
\hline Oman & 26.0 & -- & 26.0 & 7.6 & 7.4 & 7.4 & 2.8 & 6.7 & 5.1 & 2.8 & 4.6 & 3.9 & 2.3 & 6.7 & 4.8 \\
\hline Pakistan & 50.3 & -- & 50.3 & 3.3 & 4.7 & 4.0 & 1.7 & 9.8 & 5.8 & 2.5 & 4.7 & 3.6 & 1.6 & 5.1 & 3.4 \\
\hline Qatar & 46.1 & -- & 46.1 & 15.5 & 11.6 & 12.6 & 4.1 & 13.4 & 10.7 & 5.0 & 8.9 & 7.9 & 1.9 & 6.7 & 5.3 \\
\hline $\begin{array}{l}\text { Saudi } \\
\text { Arabia }\end{array}$ & 29.6 & -- & 29.6 & 10.8 & 12.6 & 11.6 & 2.7 & 7.3 & 5.1 & 2.8 & 6.4 & 4.7 & 1.2 & 5.7 & 3.6 \\
\hline Somalia & 40.5 & -- & 40.5 & 6.8 & 9.4 & 8.0 & 2.5 & 3.3 & 2.9 & 3.3 & 4.1 & 3.7 & 1.2 & 3.0 & 2.1 \\
\hline Sudan & 27.8 & -- & 27.8 & 3.2 & 6.1 & 4.6 & 1.3 & 2.7 & 2.0 & 2.7 & 6.5 & 4.5 & 1.2 & 3.5 & 2.3 \\
\hline $\begin{array}{l}\text { Syrian Arab } \\
\text { Republic }\end{array}$ & 52.5 & --- & 52.5 & 13.9 & 18.8 & 16.2 & 5.3 & 25.5 & 15.1 & 3.4 & 4.9 & 4.1 & 3.5 & 16.1 & 9.6 \\
\hline Tunisia & 31.8 & --- & 31.8 & 10.0 & 11.9 & 10.9 & 1.7 & 31.1 & 16.0 & 0.8 & 1.4 & 1.1 & 1.8 & 15.3 & 8.3 \\
\hline $\begin{array}{l}\text { United } \\
\text { Arab } \\
\text { Emirates }\end{array}$ & 39.2 & -- & 39.2 & 8.7 & 8.6 & 8.6 & 5.2 & 11.2 & 9.4 & 3.0 & 3.5 & 3.4 & 2.4 & 5.2 & 4.3 \\
\hline Yemen & 27.4 & -- & 27.4 & 3.2 & 5.9 & 4.5 & 1.7 & 6.4 & 3.8 & 2.0 & 4.1 & 2.9 & 0.3 & 3.6 & 1.8 \\
\hline
\end{tabular}

Arab Republic, and Lebanon being 25.6\%, 16.2\%, and $16.1 \%$, respectively. Also, the highest incidence rates of lung cancer were reported in Lebanon, Tunisia, Libyan Arab Jamahiriya, and Jordan being 19.8\%, 16\%, $15.7 \%$, and $15.7 \%$, respectively. The highest incidence rates of liver cancer were reported in Egypt, Qatar, and Afghanistan being 25.6\%, 7.9\%, and 5.2\%, respectively. Moreover, the highest incidence rates of bladder cancer were reported in Lebanon, Egypt, and Iraq being 16.6\%,

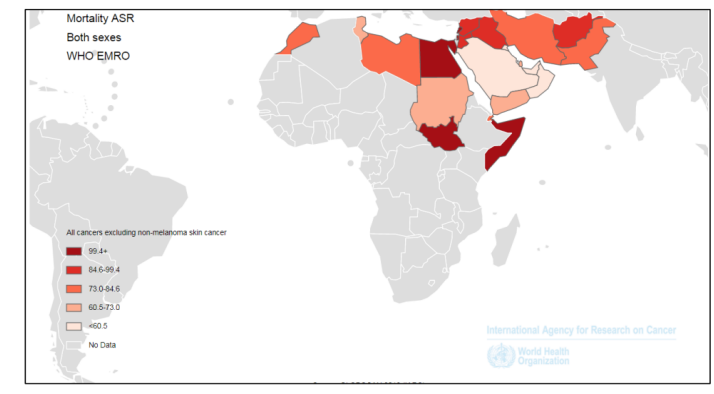

Figure 2. Distribution of the Standardized Mortality Rate of all Cancer in EMRO at 2012 (Extracted from Globocan)
$13.1 \%$, and $11.4 \%$, respectively (Table 2).

The highest mortality ratios of the overall cancers in East-Mediterranean region were reported in Somalia, Egypt, Lebanon, and Afghanistan being 106.2, 103.4, 103.2, and 97.7 cases per 100000 people, respectively as compared to the lowest mortality ratios in Saudi Arabia, Bahrain, and Kuwait being 53.9, 54.3, and 54.8 cases per 100000 people, respectively (Figure 2).

The highest mortality rates in Bothe sexes were reported for breast, colorectal, lung, liver, and bladder
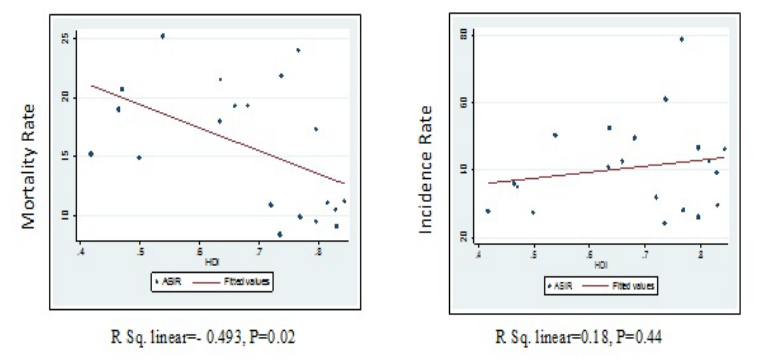

Figure 3. Correlation between the Human Development Index and Breast Cancer Incidence and Mortality Rates 
Table 3. Mortality of all Cancer in EMRO by Sex

\begin{tabular}{|c|c|c|c|c|c|c|c|c|c|}
\hline \multirow[t]{2}{*}{ Cancer Site } & \multicolumn{3}{|c|}{ Male } & \multicolumn{3}{|c|}{ Female } & \multicolumn{3}{|c|}{ Both Sexes } \\
\hline & Number & $\%$ & $\operatorname{ASR}(W)$ & Number & $\%$ & $\operatorname{ASR}(W)$ & Number & $\%$ & $\operatorname{ASR}(W)$ \\
\hline All cancers excl. nonmelanoma skin cancer & 191302 & 100.0 & 90.0 & 176139 & 100.0 & 79.4 & 367441 & 100.0 & 84.3 \\
\hline Lip, oral cavity & 6185 & 3.2 & 2.8 & 4812 & 2.7 & 2.3 & 10997 & 3.0 & 2.5 \\
\hline Nasopharynx & 1790 & 0.9 & 0.8 & 851 & 0.5 & 0.4 & 2641 & 0.7 & 0.6 \\
\hline Other pharynx & 2424 & 1.3 & 1.2 & 1555 & 0.9 & 0.7 & 3979 & 1.1 & 0.9 \\
\hline Esophagus & 8379 & 4.4 & 4.1 & 7328 & 4.2 & 3.5 & 15707 & 4.3 & 3.8 \\
\hline Stomach & 13226 & 6.9 & 6.4 & 7563 & 4.3 & 3.5 & 20789 & 5.7 & 4.9 \\
\hline Colorectal & 11768 & 6.2 & 5.5 & 9523 & 5.4 & 4.3 & 21291 & 5.8 & 4.9 \\
\hline Liver & 18893 & 9.9 & 9.3 & 9056 & 5.1 & 4.3 & 27949 & 7.6 & 6.8 \\
\hline Gallbladder & 1851 & 1.0 & 0.9 & 3282 & 1.9 & 1.6 & 5133 & 1.4 & 1.3 \\
\hline Pancreas & 4353 & 2.3 & 2.1 & 3087 & 1.8 & 1.5 & 7440 & 2.0 & 1.8 \\
\hline Larynx & 4668 & 2.4 & 2.3 & 731 & 0.4 & 0.3 & 5399 & 1.5 & 1.3 \\
\hline Lung & 22759 & 11.9 & 11.3 & 6218 & 3.5 & 2.9 & 28977 & 7.9 & 7.1 \\
\hline Melanoma of skin & 461 & 0.2 & 0.2 & 449 & 0.3 & 0.2 & 910 & 0.2 & 0.2 \\
\hline Breast & -- & -- & -- & 42228 & 24.0 & 18.6 & 42228 & 11.5 & 18.6 \\
\hline Prostate & 12141 & 6.3 & 6.2 & -- & -- & -- & 12141 & 3.3 & 6.2 \\
\hline Testis & 1438 & 0.8 & 0.5 & -- & -- & -- & 1438 & 0.4 & 0.5 \\
\hline Cervix uteri & -- & -- & -- & 7791 & 4.4 & 3.6 & 7791 & 2.1 & 3.6 \\
\hline Corpus uteri & -- & -- & -- & 2440 & 1.4 & 1.2 & 2440 & 0.7 & 1.2 \\
\hline Ovary & -- & -- & -- & 8708 & 4.9 & 4.1 & 8708 & 2.4 & 4.1 \\
\hline Kidney & 3981 & 2.1 & 1.8 & 2647 & 1.5 & 1.1 & 6628 & 1.8 & 1.5 \\
\hline Bladder & 10890 & 5.7 & 5.6 & 2932 & 1.7 & 1.4 & 13822 & 3.8 & 3.4 \\
\hline Brain,nervous system & 7792 & 4.1 & 3.3 & 5880 & 3.3 & 2.5 & 13672 & 3.7 & 2.9 \\
\hline Thyroid & 1204 & 0.6 & 0.6 & 3284 & 1.9 & 1.6 & 4488 & 1.2 & 1.1 \\
\hline Hodgkin lymphoma & 2984 & 1.6 & 1.3 & 1900 & 1.1 & 0.8 & 4884 & 1.3 & 1.01 \\
\hline Non-Hodgkin lymphoma & 10767 & 5.6 & 4.9 & 7279 & 4.1 & 3.3 & 18046 & 4.9 & 4.1 \\
\hline Multiple myeloma & 2072 & 1.1 & 1.0 & 1428 & 0.8 & 0.7 & 3500 & 1.0 & 0.9 \\
\hline Leukemia & 11577 & 6.1 & 4.5 & 8163 & 4.6 & 3.2 & & & \\
\hline
\end{tabular}

cancers being $11.5 \%, 5.8 \%, 5.9 \%, 7.6 \%$, and $3.8 \%$, respectively (Table 3).

According to the findings, HDI and incidence of lung cancer had significant correlation with each other; however, there wasn't significant correlation between HDI and incidence of breast, colorectal, liver and leukemia cancer $(\mathrm{P}>0.05)$. Moreover, results of the study showed that mortality rates of breast, colorectal, lung and liver cancer and HDI had significant correlation with each other, but significant correlation wasn't seen between mortality rate of leukemia cancer and HDI in EMRO $(\mathrm{P}>0.05)$.

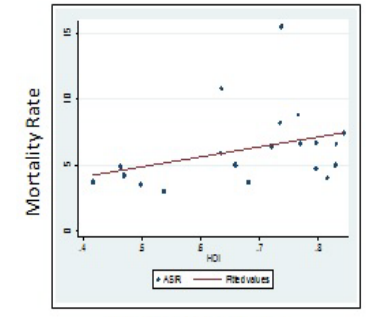

R Sq. linear $=0.455, P=0.01$

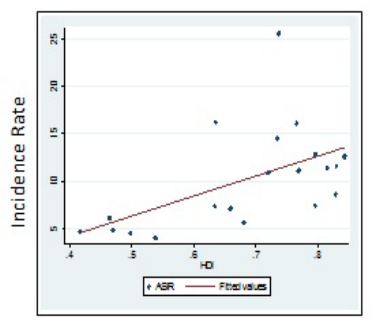

R Sq. linear $=0.350, P=0.12$

Figure 4. Correlation between the Human Development Index and Lung Cancer Incidence and Mortality Rates
Amounts related to HDI and each of its components (life expectancy at birth in 2012, the average years of schooling in 2010, and the level of income for each one of the country's population in 2012) for each of the EMRO countries is shown in Table 5.

\section{Discussion}

The cancer was considered as one of the most common types of disease reported as one of the causes of mortality all around the world [19]. Some 14.1 million new cases of
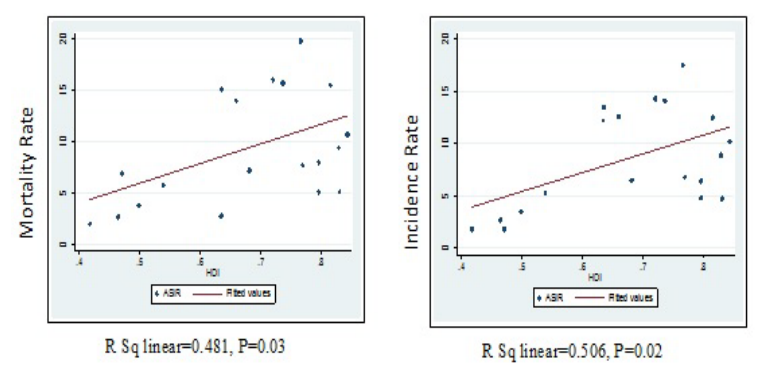

Figure 5. Correlation between the Human Development Index and Lung Cancer Incidence and Mortality Rates 
Table 4. Distribution Mortality of 5 Common Cancers in EMRO by Country and Sex

\begin{tabular}{|c|c|c|c|c|c|c|c|c|c|c|c|c|c|c|c|}
\hline \multirow[b]{2}{*}{ Areas } & \multicolumn{3}{|c|}{ Breast } & \multicolumn{3}{|c|}{ Colorectal } & \multicolumn{3}{|c|}{ Lung } & \multicolumn{3}{|c|}{ Liver } & \multicolumn{3}{|c|}{ Bladder } \\
\hline & $\mathrm{F}$ & M & $\begin{array}{c}\text { Both } \\
\text { Sexes }\end{array}$ & $\mathrm{F}$ & M & $\begin{array}{c}\text { Both } \\
\text { Sexes }\end{array}$ & F & M & $\begin{array}{l}\text { Both } \\
\text { Sexes }\end{array}$ & $\mathrm{F}$ & M & $\begin{array}{l}\text { Both } \\
\text { Sexes }\end{array}$ & $\mathrm{F}$ & M & $\begin{array}{c}\text { Both } \\
\text { Sexes }\end{array}$ \\
\hline Afghanistan & 20.7 & -- & 20.7 & 3.0 & 5.3 & 4.2 & 3.1 & 9.4 & 1.8 & 3.8 & 6.6 & 5.2 & 1.1 & 3.8 & 2.2 \\
\hline Bahrain & 11.1 & -- & 11.1 & 5 & 3.2 & 4 & 7.6 & 16.6 & 12.5 & 3.5 & 5.6 & 4.4 & 0.8 & 3.9 & 2.4 \\
\hline Djibouti & 19.0 & -- & 19.0 & 4.1 & 6.0 & 4.9 & 2.5 & 2.9 & 2.7 & 2.5 & 4.0 & 3.2 & 8.0 & 2.6 & 1.6 \\
\hline Egypt & 19.3 & -- & 19.3 & 3.4 & 4.1 & 3.7 & 3.4 & 10.1 & 6.5 & 13.3 & 37.0 & 24.5 & 2.7 & 11.1 & 6.5 \\
\hline Iran & 9.9 & -- & 9.9 & 6.3 & 6.9 & 6.6 & 4.5 & 9.1 & 6.8 & 2.0 & 2.6 & 2.3 & 1.4 & 5.5 & 3.5 \\
\hline Iraq & 19.3 & -- & 19.3 & 4.5 & 5.8 & 5.0 & 6.0 & 21.9 & 12.6 & 3.5 & 4.3 & 3.9 & 2.9 & 11.5 & 6.3 \\
\hline Jordan & 21.8 & -- & 21.8 & 13.0 & 17.9 & 15.5 & 3.7 & 24.1 & 14.1 & 2.9 & 5.2 & 4.1 & 0.9 & 5.5 & 3.2 \\
\hline Kuwait & 17.3 & -- & 17.3 & 8.6 & 5.6 & 6.7 & 3.4 & 8.3 & 6.4 & 4.2 & 5.1 & 4.8 & 1.6 & 2.5 & 2.1 \\
\hline Lebanon & 24.0 & -- & 24.0 & 7.4 & 10.5 & 8.8 & 9.6 & 26.9 & 17.5 & 1.7 & 3.1 & 2.4 & 2.4 & 11.0 & 6.3 \\
\hline Libyan Arab Jamahiriya & 8.4 & -- & 8.4 & 8.1 & 8.2 & 8.2 & 3.5 & 25.2 & 14.1 & 3.8 & 5.2 & 4.5 & 0.8 & 5.8 & 3.2 \\
\hline Morocco & 18.0 & -- & 18.0 & 5.0 & 6.9 & 5.9 & 2.5 & 22.9 & 12.2 & 0.9 & 1.5 & 1.2 & 0.7 & 6.0 & 3.1 \\
\hline Oman & 9.5 & -- & 9.5 & 4.7 & 4.8 & 4.7 & 2.8 & 6.1 & 4.8 & 2.8 & 4.6 & 3.8 & 1.2 & 3.4 & 2.5 \\
\hline Pakistan & 25.2 & -- & 25.2 & 2.5 & 3.5 & 3.0 & 1.6 & 8.7 & 5.2 & 2.5 & 4.5 & 3.5 & 1.0 & 3.1 & 2.1 \\
\hline Qatar & 11.2 & -- & 11.2 & 9.7 & 6.6 & 7.4 & 4.1 & 12.7 & 10.2 & 5.0 & 9.5 & 8.3 & 0.0 & 2.4 & 1.7 \\
\hline Saudi Arabia & 9.1 & -- & 9.1 & 6.1 & 7.3 & 6.6 & 2.5 & 6.7 & 4.7 & 2.7 & 6.3 & 4.6 & 0.5 & 2.3 & 1.4 \\
\hline Somalia & 20.6 & -- & 20.6 & 5.3 & 7.3 & 6.2 & 2.3 & 3.0 & 2.6 & 3.1 & 3.9 & 3.5 & 0.8 & 2.0 & 1.3 \\
\hline Sudan & 15.2 & -- & 15.2 & 2.5 & 5.0 & 3.7 & 1.2 & 2.4 & 1.8 & 2.6 & 6.2 & 4.3 & 0.8 & 2.5 & 1.6 \\
\hline Syrian Arab Republic & 21.5 & -- & 21.5 & 9.2 & 12.6 & 10.8 & 4.8 & 22.9 & 13.5 & 3.2 & 4.7 & 3.9 & 1.8 & 8.3 & 4.9 \\
\hline Tunisia & 10.9 & -- & 10.9 & 5.9 & 7.1 & 6.4 & 1.6 & 27.8 & 14.3 & 0.7 & 1.3 & 1.0 & 0.7 & 6.5 & 3.5 \\
\hline , United Arab Emirates & 10.5 & -- & 10.5 & 5.0 & 5.0 & 5.0 & 5.0 & 10.6 & 8.9 & 3.3 & 3.7 & 3.7 & 0.7 & 1.9 & 1.5 \\
\hline Yemen & 14.9 & -- & 14.9 & 2.5 & 4.5 & 3.5 & 1.5 & 5.8 & 3.5 & 1.9 & 4.0 & 2.9 & 0.2 & 2.4 & 1.2 \\
\hline
\end{tabular}

cancers were reported globally with the mortality rate of 8.2 million people. The studies suggested the incidence rate of cancer as 21.7 million people until 2030 with the mortality rate of 13 million people [20]. Thereupon, cancer was considered as one of the most important health problems in the world accounting for $55 \%$ of diseases' load in the developed countries [21].

The rate of incidence and prevalence of cancer were differently reported the East-Mediterranean countries as for the different levels of salary, age, risk factor difference, and various type of cancer prophylactic programs [22]. The rate of mortality and Disability-Adjusted Life Year (DALY) related to cancer in East-Mediterranean countries were estimated as $9.4 \%$ (ranged from $8.9 \%$ to $9.9 \%$ ) and $5.1 \%$ (ranged from $4.1 \%$ to $5.8 \%$ ), respectively as compared to the global rates of mortality and DALY as $15.7 \%$ (ranged from $15.5 \%$ to $15.9 \%$ ) and $8.5 \%$ (ranged

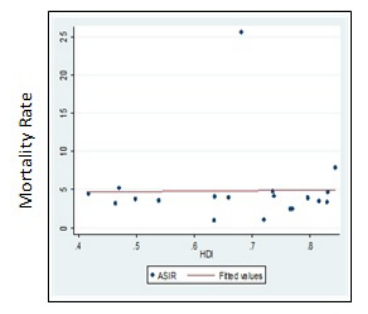

$\mathrm{R}$ Sq. linear $=0.01, \mathrm{P}=0.9$

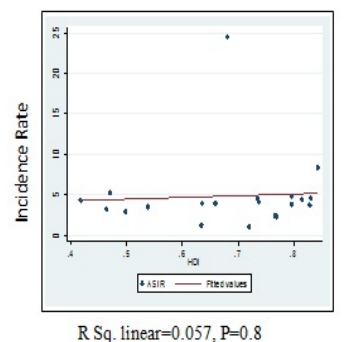

Figure 6. Correlation between the Human Development Index and Liver Cancer Incidence and Mortality Rates from $7.8 \%$ to $9.2 \%$ ) [14].

The cancer was considered as the third cause of mortality and the eighth one of DALY in EastMediterranean region. Lack of meritorious healthcare personnel, patients' financial issues, weak healthcare systems in time of war, immigrants increase and inaccessibility to the healthcare services were reported as the pivotal factors of health weakness in some countries of East-Mediterranean region [23]. The incidence rate of cancer in East-Mediterranean countries was ranged from $50 \%$ to $215 \%$ owing to different methods of incidence registration system [16-22].

The rate of cancer-related mortality was increased in East-Mediterranean countries as 32.9\% from 2005 to 2015. The rate of cancer incidence was higher in the females as compared to the higher mortality rate in the males might and mortality estimations as well as rudimentary cancer
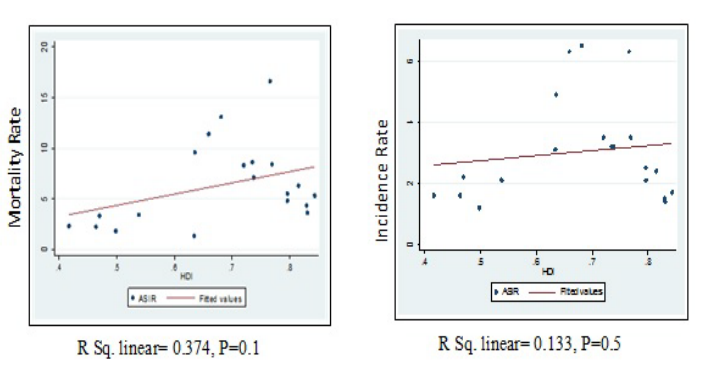

Figure 7. Correlation between the Human Development Index and Bladder Cancer Incidence and Mortality Rates 
Table 5. HDI and Its Component in EMRO Countries

\begin{tabular}{lcccc}
\hline Country & Life expectancy at birth & Mean year of schooling (years) & GNI per capita (\$) & HDI \\
\hline Afghanistan & 60.5 & 3.1 & 1000 & 0.47 \\
Bahrain & 76.5 & 9.4 & 19154 & 0.815 \\
Djibouti & 61.3 & --- & 3109 & 0.464 \\
Egypt & 64.2 & --- & 10400 & 0.681 \\
Iran & 73.7 & 7.8 & 10695 & 0.769 \\
Iraq & 69.2 & 5.6 & 3557 & 0.659 \\
Jordan & 73.7 & 8.6 & 5272 & 0.737 \\
Kuwait & 74.2 & 6.1 & 52793 & 0.769 \\
Lebanon & 79.7 & 7.9 & 12364 & 0.766 \\
Morocco & 70.7 & --- & 6905 & 0.634 \\
Oman & 76.3 & 5.5 & 24092 & 0.796 \\
Pakistan & 66.4 & 4.9 & 2566 & 0.538 \\
Qatar & 78.2 & 7.3 & 87478 & 0.843 \\
Saudi Arabia & 75.3 & 7.8 & 22616 & 0.83 \\
Sudan & 61.9 & --- & 3428 & 0.417 \\
Syrian Arab Republic & 74.5 & 5.7 & 4674 & 0.635 \\
Tunisia & 75.9 & --- & 10440 & 0.72 \\
United Arab Emirates & 76.7 & 8.9 & 42716 & 0.829 \\
Yemen & 62.9 & 5.3 & 928 & 0.498 \\
\hline
\end{tabular}

be due to the breakout of less invasive cancers in females (e.g. breast and cervix cancers) and more invasive cancers in males (e.g. lung and stomach) [22-24-25].

Some 555318 cases of cancer were registered in EastMediterranean region in 2012. The highest rates of cancer in both genders were related to breast, colo-rectum, lung, liver, and bladder being $17.9 \%, 5.9 \%, 5.9 \%, 5.3 \%$, and $5 \%$, respectively.

The highest incidence ratios of cancer in EastMediterranean region were reported for Lebanon, Jordan, Egypt, and Syrian Arab Republic being 197.4, 155.4, 152 , and 145.9 cases per 100000 people, respectively as compared to the lowest incidence ratios in Yemen, and Oman being 80.4 , and 82.1 cases per 100000 people, respectively. Moreover, the highest mortality ratios of cancer were reported for Somalia, and Egypt being 106.2 , and 103.4 cases per 100000 people, respectively as compared to the lowest mortality ratios in Saudi Arabia, and Bahrain being 53.9, and 54.3 cases per 100000 people, respectively.

Studies reported the tobacco, inappropriate nutritional regimen, Body Mass Index, occupational dangers, and weather contamination as the cancer determinants in East-Mediterranean region [26-27]. The lung cancer was reported as the third cause of mortality in EastMediterranean region in which tobacco usage was indicated as the main risk factor of it [28-29]. Inappropriate life style and physical inactivity were reported as the main causes of colorectal cancer [30]. Obesity was indicated as the risk factor of esophagus, colon, rectum, kidney, and pancreas cancers. Gall bladder cancer was demonstrated as the risk factor of breast, ovary, and uterus cancers [31].

The breast cancer was reported as the most common type of cancer in East-Mediterranean region. Colorectal cancer was indicated as the second commonest type of cancer emphasizing on the appropriate health programs, environmental policies, physical activity increase, and healthy life style. Other primary prophylactic approaches are including Human Papilloma Virus (HPV) vaccination to prevent cervix cancer and Hepatitis $B$ vaccination as well as Hepatitis B and C treatment especially in countries with high rates of Hepatitis $\mathrm{C}$ like Egypt so as to reduce the incidence of liver cancer [32]. Accessible screening programs for cervix, colorectal, breast, mouth, and stomach cancers are being performed could play an important role in diagnosing the disease in primary stages and reducing the mortality rate consequently [33].

Our study indicated that to increase in HDI causes reduction in mortality rate of breast cancer; however, increasing in HDI leads to higher incidence and mortality rate of colorectal cancer. Many studies have represented that mortality rate of breast cancer is lower in developed countries compared to developing and underdeveloped countries due to screening programs, proper treatment, availability of health and medical services and changing in lifestyle [34-35]

Distribution of cancer based on HDI can be used for prevention of cancer in each country.

Cancer was reported in all of age groups although generally indicated in old-aged people. Therefore, the rate of cancer might significantly be higher in regions with elder population. The standard age range of cancer incidence varies in East-Mediterranean countries. The highest incidence rates of cancer in both genders in East-Mediterranean region were reported for 75- and over-75 year-old age group in 2012 . The population aging and increasing life expectancy in the most countries of East-Mediterranean region could be considered as the 
factors of this increase.

In conclusion, Cancer was considered as one of the main causes of mortality in the most countries of EastMediterranean region. The breast and colorectal cancers were reported as the most common types of cancer in East-Mediterranean region. As for the alarming trend and remarkable distribution of cancer to the disease load in East-Mediterranean countries, controlling the cancer should be considered as one of the priorities of health policy. Performing the screening programs, Hepatitis and Papilloma viruses' vaccination, changing life style, increasing physical activity and using the healthy nutritional regimen could decrease the rate of cancers. Thereupon, the rates of cancer incidence and mortality could be declined in East-Mediterranean countries through performing the 1st-level prophylactic programs, screening programs, early diagnosis and treatment as well as 3rdlevel prophylactic programs.

\section{Acknowledgments}

This paper used data from the GLOBOCAN and the United Nations development programme (UNDP). The authors declare that there is no conflict of interests to report for this work.

\section{Conflict of Interest}

None.

\section{References}

1. Kamangar F, Dores GM, Anderson WF. Patterns of cancer incidence, mortality, and prevalence across five continents: defining priorities to reduce cancer disparities in different geographic regions of the world. Journal of clinical oncology. 2006;24(14):2137-50.

2. Yari S, Fallah AA, Varmazyar S. Assessment of semiquantitative health risks of exposure to harmful chemical agents in the context of carcinogenesis in the latex glove manufacturing industry. Asian Pacific journal of cancer prevention: APJCP. 2015;17(205):11.

3. Yari S, Asadi AF, Normohammadi M. Occupational and Environmental Cancer. Asian Pacific Journal of Environment and Cancer. 2018;1(1).

4. Yari S, Asadi AF, Jarrahi AM, Normohammadi M. CARcinogen EXposure: CAREX. Asian Pacific Journal of Environment and Cancer. 2018;1(1).

5. Normohammadi M, Asadi AF. Job Stress and Safety Climate in Cancer Treatment Centers: Upgraded Model for Dimensions. Asian Pacific Journal of Environment and Cancer. 2018;1(2).

6. Yari S, Naseri MH, Akbari H, Shahsavari S, Akbari H. Interaction of Safety Climate and Safety Culture: A Model for Cancer Treatment Centers. Asian Pacific Journal of Cancer Prevention. 2007;20(3):961-9.

7. Antoni S, Ferlay J, Soerjomataram I, Znaor A, Jemal A, Bray F. Bladder cancer incidence and mortality: a global overview and recent trends. European urology. 2017;71(1):96-108.

8. Khazaei Z NH, Goodarzi E, Khoshakhlagh Z, Khazaei S, Jabari E, et al. Investigating self-care performance of diabetic patients at a diabetes center; a single center pilot study. J Nephropharmacol. 2018;7(1):7-14. J Nephropharmacol. 2018;7(1):7.

9. organization WH. Global Health Risks-Mortality and burden of disease attributable to selected major risks. Cancer. 2017.

10. Li Z, Yang L, Du C, Fang X, Wang N, Gu J. Characteristics and comparison of colorectal cancer incidence in Beijing with other regions in the world. Oncotarget. 2017;8(15):24593.

11. Momenabadi V KM, Khazaei Z, Nazari Robati F, Shakerian M. . The association between self-efficacy and self-care behaviors among elderly with diabetes as a modality to reduce diabetic complication; a population-based study with regard to control of diabetic nephropathy. diabetic nephropathy J Nephropharmacol. 2018;7(1):7-16.

12. Hassanipour-Azgomi S, Mohammadian-Hafshejani A, Ghoncheh M, Towhidi F, Jamehshorani S, Salehiniya $\mathrm{H}$. Incidence and mortality of prostate cancer and their relationship with the Human Development Index worldwide. Prostate international. 2016;4(3):118-24.

13. Chaichian S, Khateri S, Moradi Y, Shadmani FK, Mansori $\mathrm{K}$, Khazaei $\mathrm{Z}$, et al. Trends in cervical cancer incidence in Iran from 2003 to 2009. Middle East Journal of Cancer. 2017;9(1):57-63.

14. Borji A, Bayat M, Shamsabadi F, Amini F, Dayyani M, Mehrad Majd H. Epidemiology of Gastrointestinal Cancers (Stomach, Esophageal and Colorectal) in Neyshabur City during 2006-2012. J Neyshabur Univ Med Sci. 2016;3(4):3744.

15. Arabsalmani M, Mohammadian-Hafshejani A, Ghoncheh M, Hadadian F, Towhidi F, Vafaee K, et al. Incidence and mortality of kidney cancers, and human development index in Asia; a matter of concern. Journal of nephropathology. 2017;6(1):30.

16. Ferlay J, Soerjomataram I, Dikshit R, Eser S, Mathers C, Rebelo M, et al. Cancer incidence and mortality worldwide: sources, methods and major patterns in GLOBOCAN 2012. International journal of cancer. 2015;136(5).

17. Bray F, Jemal A, Grey N, Ferlay J, Forman D. Global cancer transitions according to the Human Development Index (2008-2030): a population-based study. The lancet oncology. 2012;13(8):790-801.

18. Khazaei S, Rezaeian S, Khazaei Z, Molaeipoor L, Nematollahi S, Lak P, et al. National Breast cancer mortality and incidence rates according to the human development index: an ecological study. Advances in Breast Cancer Research. 2016;5(01):30.

19. Rahimi Pordanjani S, Baeradeh N, Khazaei Z, Goodarzi E, Beiranvand R, Alikhani A, et al. Epidemiological Trend and Distribution of Prevalent Cancers in Razavi Khorasan Province during 2005-2010, Iran. International Journal of Preventive and Public Health Sciences. 2017.

20. Pakzad R, Mohammadian-Hafshejani A, Mohammadian M, Pakzad I, Safiri S, Khazaei S, et al. Incidence and mortality of bladder cancer and their relationship with development in Asia. Asian Pac J Cancer Prev. 2015;16(16):7365-74.

21. Ferlay J, Héry C, Autier P, Sankaranarayanan R. Global burden of breast cancer. Breast cancer epidemiology: Springer; 2010. p. 1-19.

22. Fitzmaurice C. Burden of cancer in the Eastern Mediterranean Region, 2005-2015: findings from the Global Burden of Disease 2015 Study. International Journal of Public Health. 2017:1-14.

23. Wang H, Naghavi M, Allen C, Barber R, Carter A, Casey $\mathrm{D}$, et al. Global, regional, and national life expectancy, all-cause mortality, and cause-specific mortality for 249 causes of death, 1980-2015: a systematic analysis for the Global Burden of Disease Study 2015. The Lancet. 2016;388(10053):1459-544.

24. Kulhánová I, Bray F, Fadhil I, Al-Zahrani AS, El-Basmy A, Anwar WA, et al. Profile of cancer in the Eastern 
Mediterranean region: The need for action. Cancer epidemiology. 2017;47:125-32.

25. Vos T, Allen C, Arora M, Barber RM, Bhutta ZA, Brown A, et al. Global, regional, and national incidence, prevalence, and years lived with disability for 310 diseases and injuries, 1990-2015: a systematic analysis for the Global Burden of Disease Study 2015. The Lancet. 2016;388(10053):1545602.

26. Forouzanfar MH, Alexander L, Anderson HR, Bachman VF, Biryukov S, Brauer M, et al. Global, regional, and national comparative risk assessment of 79 behavioural, environmental and occupational, and metabolic risks or clusters of risks in 188 countries, 1990-2013: a systematic analysis for the Global Burden of Disease Study 2013. The Lancet. 2015;386(10010):2287-323.

27. Khazaei S, Mansori K, Soheylizad M, Gholamaliee B, Shadmani FK, Khazaei Z, et al. Epidemiology of lung cancer in Iran: sex difference and geographical distribution. Middle East Journal of Cancer. 2017;8(4):223-8.

28. Etemadi A, Khademi H, Kamangar F, Freedman ND, Abnet CC, Brennan P, et al. Hazards of cigarettes, smokeless tobacco and waterpipe in a Middle Eastern Population: a Cohort Study of 50000 individuals from Iran. Tobacco control. 2016:tobaccocontrol-2016-053245.

29. Heydari G, Talischi F, Masjedi M, Alguomani H, Joossens L, Ghafari M. Comparison of tobacco control policies in the Eastern Mediterranean countries based on Tobacco Control Scale scores. 2012.

30. Ng M, Fleming T, Robinson M, Thomson B, Graetz N, Margono C, et al. Global, regional, and national prevalence of overweight and obesity in children and adults during 1980-2013: a systematic analysis for the Global Burden of Disease Study 2013. The lancet. 2014;384(9945):766-81.

31. Lauby-Secretan B, Scoccianti C, Loomis D, Grosse Y, Bianchini F, Straif K. Body fatness and cancer-viewpoint of the IARC Working Group. New England Journal of Medicine. 2016;375(8):794-8.

32. Alavian SM, Haghbin H. Relative importance of hepatitis b and $\mathrm{c}$ viruses in hepatocellular carcinoma in EMRO countries and the middle east: a systematic review. Hepatitis monthly. 2016;16(3).

33. Sankaranarayanan R. Screening for cancer in low-and middle-income countries. Annals of global health. 2014;80(5):412-7.

34. Ferlay J, Soerjomataram I, Dikshit R, Eser S, Mathers C, Rebelo M, et al. Cancer incidence and mortality worldwide: sources, methods and major patterns in GLOBOCAN 2012. International journal of cancer. 2015;136(5):E359-E86.

35. Cheng ML, Zhang L, Borok M, Chokunonga E, Dzamamala $\mathrm{C}$, Korir A, et al. The incidence of oesophageal cancer in Eastern Africa: identification of a new geographic hot spot? Cancer epidemiology. 2015;39(2):143-9.

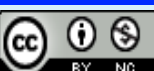

This work is licensed under a Creative Commons AttributionNon Commercial 4.0 International License. 